\title{
Research on Professional Reform of $1+$ X Certificate Based on Web Front End
}

\author{
Chao Liu and Dinghua He*
}

\author{
Department of Computer, Wuhan polytechnic, Wuhan 430074, China \\ *Corresponding author.Email: hedinghua@qq.com; ${ }^{\text {*5 } 5221529027 @ q q . c o m}$
}

\begin{abstract}
In order to cultivate high-level application-oriented talents, the Ministry of Education promulgated the National Vocational Education Reform Implementation Plan. The plan will launch the implementation of the " $1+\mathrm{X}$ " certificate system reform and the plan for building high-level vocational colleges and majors with Chinese characteristics. 1 refers to the graduation certificate, and $\mathrm{X}$ refers to multiple professional qualifications. This paper describes the research on curriculum reform based on $1+\mathrm{X}$ in the major of $\mathrm{Web}$ front-end engineer.
\end{abstract}

Keywords: Web front-end major, The back end of the website, Curriculum system, The curriculum reform.

\section{INTRODUCTION}

\subsection{Introduction to This Project}

On February 19, 2019, the Ministry of Education issued the National Vocational Education Reform Implementation Plan. The plan will launch the implementation of high-level vocational colleges and major construction plan with Chinese characteristics and the reform of the " $1+x$ " certificate system, so as to truly cultivate high-quality talents urgently needed by the society. 1 refers to the education certificate, $\mathrm{X}$ refers to the qualification certificate which represents a certain technical skill, different majors correspond to different qualifications.

In order to implement the Implementation Plan of National Vocational Education Reform, The Web front end development engineer of the Department of Computer of Wuhan Polytechnic participated in the Web front end $1+\mathrm{X}$ intermediate and elementary examinations organized by the Ministry of Industry and Information Technology. And achieved gratifying results, won the country's two first. The pass rate was $59 \%$, the highest in the country, and the national average was only $29 \%$. The highest score in our school ranks the first in China.

Web front end $1+X$ certificate has a very high gold content, is the ministry of Education, the Ministry of Industry and Information Technology to promote the vocational qualification certificate. Web front end $1+\mathrm{X}$ certificates include junior certificates, intermediate certificates, and senior certificates. The primary certificate mainly involves front-end courses, including HTML5 program design, JavaScript program design foundation, CSS foundation and other courses. The intermediate certificate mainly involves CSS, JavaScript programming, PHP programming, laravel framework, MySQL database and other contents, and the later courses are mainly. The intermediate certificate is in line with the orientation of high quality students of Wuhan polytechnic. The good results obtained in the Web front-end $1+X$ certificate for the first time in Wuhan Vocational and Technical College further prove that the students of our school are fully capable of achieving better results in the intermediate certificate.

The Intermediate certificate of Web front-end $1+\mathrm{X}$ mainly involves several courses of Web back-end, including PHP programming and lavavel framework development. Front-end courses and back-end courses are closely related. Students in our school have learned HTML5 programming, JavaScript programming and CSS before participating in the Web front-end $1+\mathrm{X}$ certificate. Therefore, the Web front-end $1+\mathrm{X}$ intermediate certificate focuses on PHP programming, laravel framework, MySQL database and other back-end courses.

The course team will make bold changes to the Web1+X intermediate course system, including course content reform (which back-end courses to offer, which semester to offer, and what to talk about), teaching 
method reform (how to speak), and exam reform (how to test). We'll talk more about that later.

\subsection{The Practical and Theoretical Significance of This Project}

In order to adapt to the Implementation Plan of National Vocational Education Reform, the Major of Web front-end development Engineer in the department of Computer science of our college will reform the course of Web front-end development Engineer. This course group will focus on the back-end based curriculum reform. The practical significance of curriculum reform is mainly embodied in three aspects.

Firstly,the implementation of the project is reflected in the cultivation of high-quality talents needed by the society. The Implementation Plan of National Vocational Education Reform issued by the Ministry of Education puts forward higher requirements for talents training in colleges and universities. Wang Yang-nan, director of the Institute of Vocational Education Center of the Ministry of Education, pointed out at the press conference of the Implementation Plan of National Vocational Education Reform that vocational skill level certificate is an important content of $1+\mathrm{X}$ certificate system design and a new type of certificate. The training and evaluation organizations shall connect with professional standards, conform to international advanced standards, develop vocational skill level standards according to relevant regulations, and be responsible for the implementation of vocational skill assessment, evaluation and issuance of certificates. Today's social workplace competition is fierce, professional skills certificate is an important certificate of personal ability evaluation, assessment, employment and from the job, is the qualification certificate of job, is also the workplace "stepping stone", is the main basis for employing units to recruit, hire. The reform of " $1+x "$ certificate system of vocational skill certificate fully shows that the country attaches great importance to vocational education, and favorable policies will increase employment security for vocational education students. This kind of high-quality talents is mainly reflected in the fact that the trained talents get the rich textual research, because this textual research examines the advanced and systematic content taught by the school. Got the employer's approval. The high quality of such talents is also reflected in the compact and reasonable results of the curriculum system. For example, the Web Front-end $1+X$ intermediate course contains the Web front-end $1+\mathrm{X}$ elementary course, and the two are closely related. Advanced courses also include intermediate courses. The purpose of this is to ensure the consistency, compactness and comprehensiveness of the curriculum system.

Secondly,the implementation of this project is of positive significance to the upgrading of vocational students.At an executive meeting of the State Council held by Premier Li Ke-qiang on February 25, 2020, it was pointed out that more attention should be paid to stable employment, especially for key groups such as college graduates and migrant workers. This year, we will increase the number of graduate students we recruit and the number of graduate students who will be promoted to graduate students. We will increase the number of medical and social service positions at the community level. Provinces have introduced relevant policies. As we all know, in the current epidemic prevention and control of environment, many traditional industries suffered from a deadly blow, graduate employment environment, at the same time there are 8.74 million college graduates in 2020, an increase of 400000 year on year, increasing the employment difficulty, in this case, through the education alleviate current pressure on employment, social risk, but also to meet the needs of the current national development of high-quality talent, is also a way of improving the quality of population as a whole. Higher vocational students who have obtained the Web front-end $1+\mathrm{X}$ intermediate certificate in accordance with relevant documents of the Ministry of Education can be exempted from taking six courses (PHP programming, JavaScript programming, CSS, MySQL, HTML5 programming, laravel Framework) during their undergraduate study. Therefore, the curriculum reform of Web front-end engineer in our university is of positive significance to the upgrading of higher vocational students, which is reflected in the entrance examination of specialized courses and the reduction of academic burden after entering undergraduate colleges.

Thirdly, the professional reform of Web front-end development engineer makes the course system more systematic and scientific and the arrangement of content and time more compact and reasonable. For example, PDO access to the database was not arranged in the course PHP Programming of our school before, while a large number of PDO tests appeared in the intermediate certificate, which requires us to reform the existing course content, which is not a simple addition or subtraction. You also need to integrate the course content organically, for example, when you talk about functions, you only talk about functions that are required in the project, in the exam, in the syllabus. Other functions students can learn by themselves according to the manual. This requires teachers to be familiar with the whole curriculum system. In addition, our school did not offer "laravel Framework" before (it was a ThinkPHP domestic framework). According to the authoritative data of education and Examination Center of ministry of Industry and Information Technology in 2019 and the Web1+X examination questions, ThinkPHP is no longer required, but replaced by "laravel Framework". The course team will make bold modifications to PHP Programming in accordance with the relevant spirit of the Ministry of Education and the Ministry of Industry and Information Technology, and resolutely cancel the ThinkPHP 
framework and set up laravel framework. There are three advantages to this. First, it is easier for students to get the certificate. Second, the curriculum system is more scientific; thirdly, students are more popular with enterprises.

Fourth, it provides Suggestions and construction ideas for the $1+x$ certificate of other newly opened majors. For example, in June 2020, the School of Computer Network security $1+\mathrm{X}$ was approved by the Department of Education. And network security major and Web front end major still have a few common courses. For example, PHP Programming, the construction and reform of the $1+\mathrm{X}$ course of the Web front end just provides construction experience and teaching resources for other similar $1+X$ certificate and professional construction.

\section{THE BASIC CONTENT OF THE SUBJECT RESEARCH}

\subsection{Curriculum System Reform and Curriculum Content Reform of Web Front End Development Engineer Specialty}

The curriculum system of Web front-end development engineer is mainly divided into front-end courses and back-end courses. The back-end courses include Linux operating system, PHP programming, laravel framework, MySQL database, and the use of various application software and development platforms. There will also be some front end content in the back end.

The research group should study the reform of the course system, such as whether the MySQL programming should be integrated with PHP programming, whether the class hours of PHP programming should be increased, or whether the class hours should be increased by recording courses. And the chronology of the courses. In addition, the research work is to determine the content to be taught in the back-end course system and refine it to the most basic knowledge points. For example, which functions need to be explained and which functions don't. What sections need to be explained, what needs to be taught by students, and so on.

The curriculum system reform also needs to consider the time node of Web front-end development engineer $1+X$ of the Ministry of Industry and Information Technology, which will be duly fine-tuned in the subsequent curriculum reform.

\subsection{Reform of Teaching Methods}

Integrated teaching in computer room and video course; the courses recorded and broadcasted include both courses recorded by our teachers and video resources downloaded from the Internet. There are even cases where teachers and students study at the same time. The reason is the emergence of new questions and the constant updating of course content. Teachers also need to constantly update their knowledge base. This is bound to lead to learning by learning by teaching. It's a big challenge for teachers. The basic content of the research group is to refine the teaching content, assign tasks, and record videos and classify videos in advance.

Hierarchical teaching; The Web1+X exam organized by the Ministry of Industry and Information Technology will be held in two batches in 2019. The first group of participants were the top performers in the class of 2018. The second batch of students and the first batch of students who did not pass the examination. Then there is the problem of hierarchical teaching. Our idea is to gather the top students in the whole grade of Web front end for closed training without affecting the overall learning progress and learning order. Teaching is faster and more advanced. In the pilot test in 2019, our school ranked first in the country twice. This was achieved when students studied for only four weeks and received intensive training for only one week. Classroom teaching and closed intensive training are hierarchical teaching. Different teaching contents, difficulties and speeds. The basic content of the research group is to refine the hierarchical teaching content to each class and study the possibility of further deepening the hierarchical teaching

Combine teaching, learning and practice; The Web1+ $\mathrm{X}$ examination questions of the Ministry of Industry and Information Technology mainly include objective questions and subjective questions. Objective questions are mainly multiple choice questions and judgment questions. Subjective questions are programming questions and fill in the blanks. The members of the course group collected a large number of topics for students to brush and explained the topics to students through technical means, which achieved very good results. The next step of the research group is to further expand the question bank, select the question bank, and make the answers, so as to make a good preparation for teaching questions to students in the future.

\subsection{Examination and Evaluation Reform}

For candidates who have passed the Intermediate certificate of Web1+X, a communication mechanism should be established for their textual research and final exam scores. The research group should study the communication mechanism between intermediate certificate scores and final exam scores of laravel framework, so as to build a communication bridge between them. On the one hand, it should improve the enthusiasm of students, and on the other hand, it should ensure that the communication mechanism does not produce new contradictions. Second, consider the conflict between the late arrival of Web1+X certificate scores and the early arrival of the final exam. 


\section{RESEARCH METHODS}

\subsection{Research Methods}

Investigation method: The research group will collect the policies of the Ministry of Education and the Ministry of Industry and Information Technology in a purposeful, planned and systematic way. Collect Web1+X question bank and question type. In combination with the talent training program for Web front-end development engineers, we should adjust the research content and reform direction to match the national policy, talent training and examination as much as possible. To investigate brother universities and enterprises, collect first-hand data, timely adjust the content of back-end courses, and cultivate high-quality students welcomed by enterprises.

Literature method: consult literature materials, research learning methods, teaching methods, research course reform direction. Write research papers and research reports. Collect student learning materials, manuals, documentation, and key codes, and package and share learning resources with students.

\subsection{Technical Route}

1. Understand national policies. On February 19, 2019, the Ministry of Education issued the National Vocational Education Reform Implementation Plan. The plan will launch the implementation of the high-level vocational colleges and major construction plan with Chinese characteristics and the reform of the " $1+\mathrm{X} "$ certificate system, combining documents and certificates, so as to truly cultivate high-quality talents in urgent need of the society.

2. Develop curriculum reform plans. In the summer vacation of 2019, Wang Hai, President of The College of Computer Science, and Deng Xiaofei, director of the Network Teaching and Research Office, made a decisive decision to reform the course system according to the national policy. For example, cut ThinkPHP Framework and add laravel Framework.

3. Develop teacher training plans. Carry out teacher training plan according to the curriculum reform plan. During the summer vacation, teachers from the computer network Web front end took advantage of the vacation to receive professional training. Teachers such as Deng Xiaofei, Ren Yong and He Dinghua participated in the training of their own courses. And recorded the course teaching video.

4. Implement the new talent training program after the reform. In the first semester of the 2019-2020 academic years, the course group implemented a new talent training program for four classes, including Network 18301-Network 18304. Teaching laravel framework, hierarchical teaching (classroom teaching and closed intensive training).

5. The inspection. Students of our school participated in the Web front end $1+\mathrm{X}$ intermediate examination of the Ministry of Industry and Information Technology and got excellent results. Further professional and curriculum reform. In order to consolidate the results, further optimize the curriculum system, especially the back-end curriculum system. The research group will apply for this project, and further carry out curriculum reform, keep grasping national policies and professional technology development trends, and timely adjust the curriculum system and curriculum content.

\section{CONCLUSION}

The curriculum reform based on $1+X$ certificate in the Web front-end development major will cultivate high-quality talents required by the society, which will have positive significance for students' upgrading and teachers' professional quality improvement.

\section{ACKNOWLEDGMENT}

This research was financially supported by the 2020 project of Wuhan polytechnic, project Number: 2020YJ010.

\section{REFERENCES}

[1] https://baijiahao.baidu.com/s?id=16595246515732 $25261 \& w f r=$ spider $\&$ for $=p c$

[2] https://baijiahao.baidu.com/s?id=16401698340735 $75254 \& w f r=$ spider $\&$ for $=p c$

[3] http://www.moe.gov.cn/fbh/live/2019/50294/mtbd/ 201902/t20190220_370251.html

[4] https://baijiahao.baidu.com/s?id=16417849025159 $82254 \& w f r=$ spider $\&$ for $=$ pc

[5] http://www.gov.cn/fuwu/2019-04/17/content_5383 660.htm

[6] http://www.moe.gov.cn/jyb_xwfb/s5147/201904/t2 0190417_378393.html

[7] https://baijiahao.baidu.com/s?id=16309629265418 $96099 \& w f r=$ spider $\&$ for $=p c$ 